7-15-2020

\title{
Effects of COVID-19 on nutrition in Bihar
}

UNICEF

Population Council Institute

Follow this and additional works at: https://knowledgecommons.popcouncil.org/departments_sbsr-pgy

Part of the Demography, Population, and Ecology Commons, International Public Health Commons, and the Public Health Education and Promotion Commons How does access to this work benefit you? Let us know!

\section{Recommended Citation}

UNICEF and Population Council Institute. 2020. "Effects of COVID-19 on nutrition in Bihar," COVID-19 Research Results Brief \#4. New Delhi: UNICEF and Population Council Institute.

This Brief is brought to you for free and open access by the Population Council. 


\section{EFFECTS OF COVID-19 ON NUTRITION IN BIHAR}

Half of the households in Bihar reported food shortage in the past month, causing most of them to reduce food intake; overall, three out of five reported reduced food intake.

Support from government nutrition schemes such as take-home ration for pregnant women and small children, and mid-day meals for school-going children need to improve the coverage.

\section{Food shortage during the lockdown and the} consequent reduction in food intake were reported more commonly by marginalised populations and people who lost income than others. Income support or opportunities for these groups may be prioritised.

\section{IMPACT OF LOCKDOWN ON FOOD INTAKE IN HOUSEHOLD}

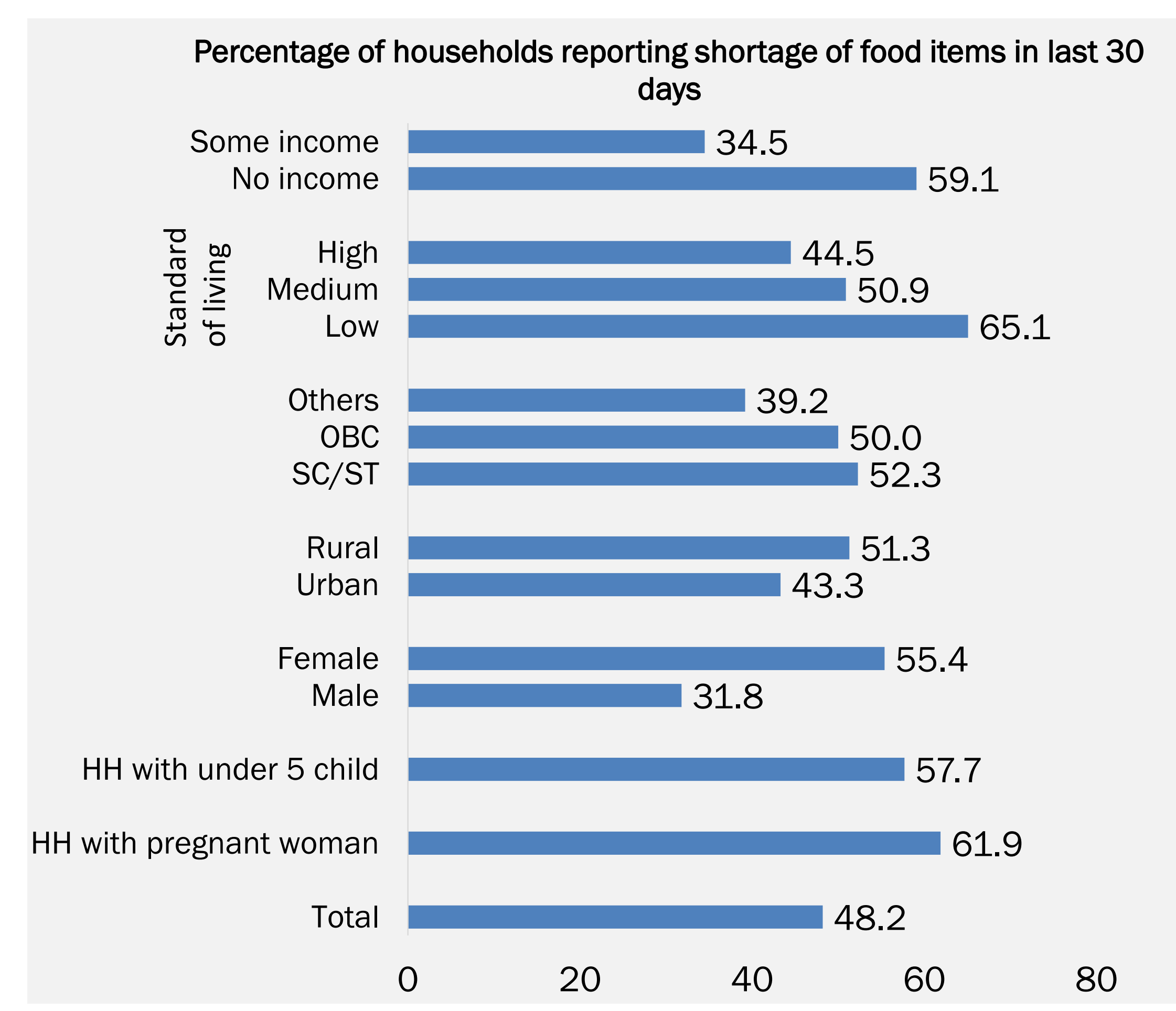

Notes: All differences are statistically significicant at $5 \%$ or better; The question on
income: What is the source of income of the family during the lockdown?

- $1 / 2$ (48.2\%, 95\% Cl: 44.8, 51.7) households reported food shortage in past month; higher among households with pregnant women, under 5 year old children, rural, marginalised, economically weaker households and those with lost income.

- $1 / 2$ of females versus $1 / 3$ of males reported shortage of food and reduced intake.

- $3 / 5$ (59.2\%, 95\% Cl: 55.8,62.6) households reported reduced food intake during economically weaker households and those who lost income.

- 9/10 households compromised in consumption of vegetables or flesh foods.

1/3 (36.1\%, 95\% Cl: 31.3, 40.8) eligible households received take home ration in the past month; slightly higher among rural and marginalised households.

- Three out of five (Mean 2.9, 95\% Cl: 2.8,3.1) recommended food groups were consumed by pregnant women on the day before the survey; least likely to consume dairy products and flesh foods.

- 1/3 (29\%, 95\% Cl: 22.2, 35.7) households with a child aged $6-14$ years reported receiving cash in lieu of mid-day meals.

Receiving cash in lieu of mid-day meal was equally reported by eligible households in both rural and urban areas; however, higher proportion of males (35\%) than females $(26 \%)$ reported so.

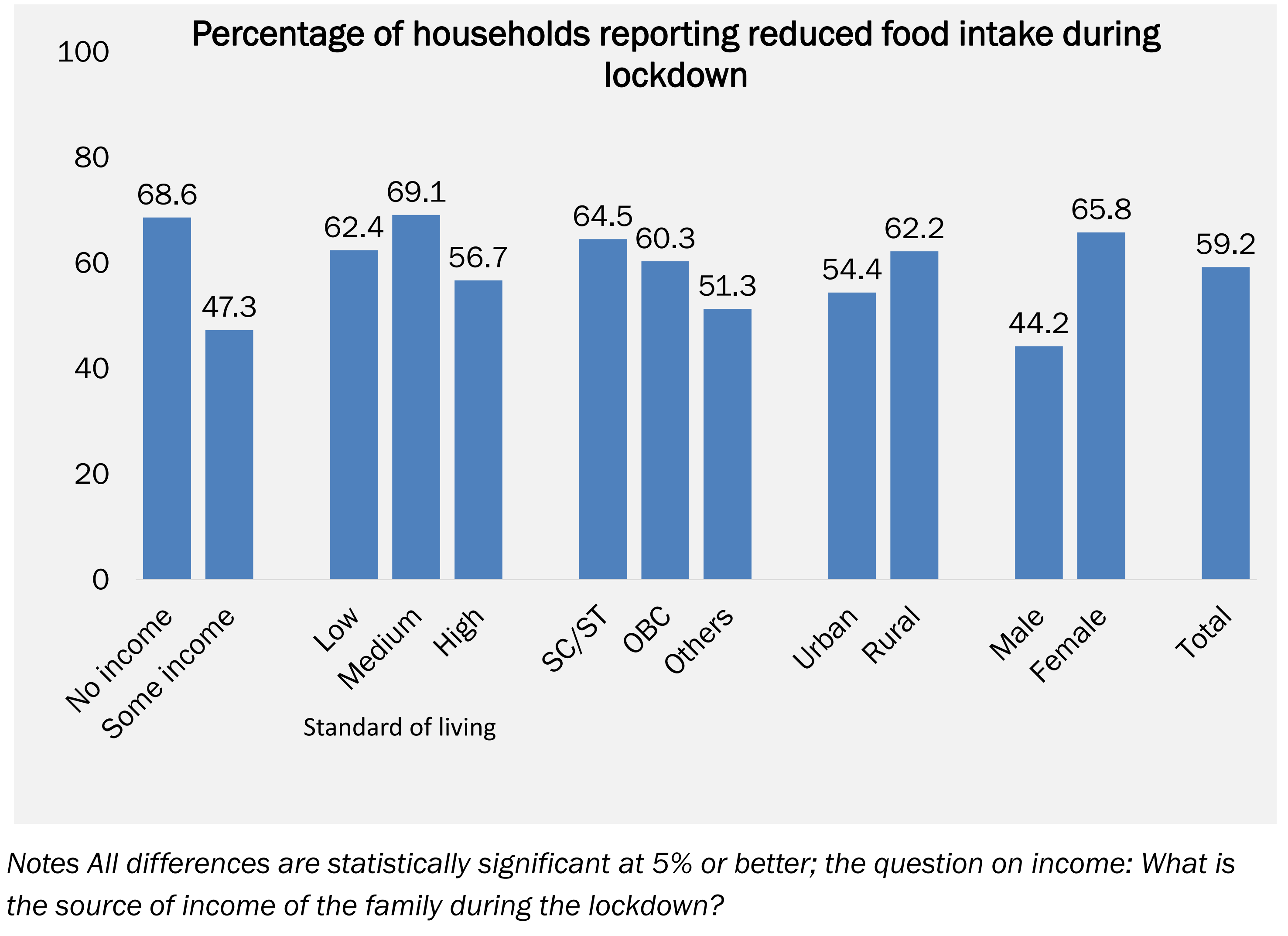

Percentage of households reporting reduced consumption of food groups during lockdown
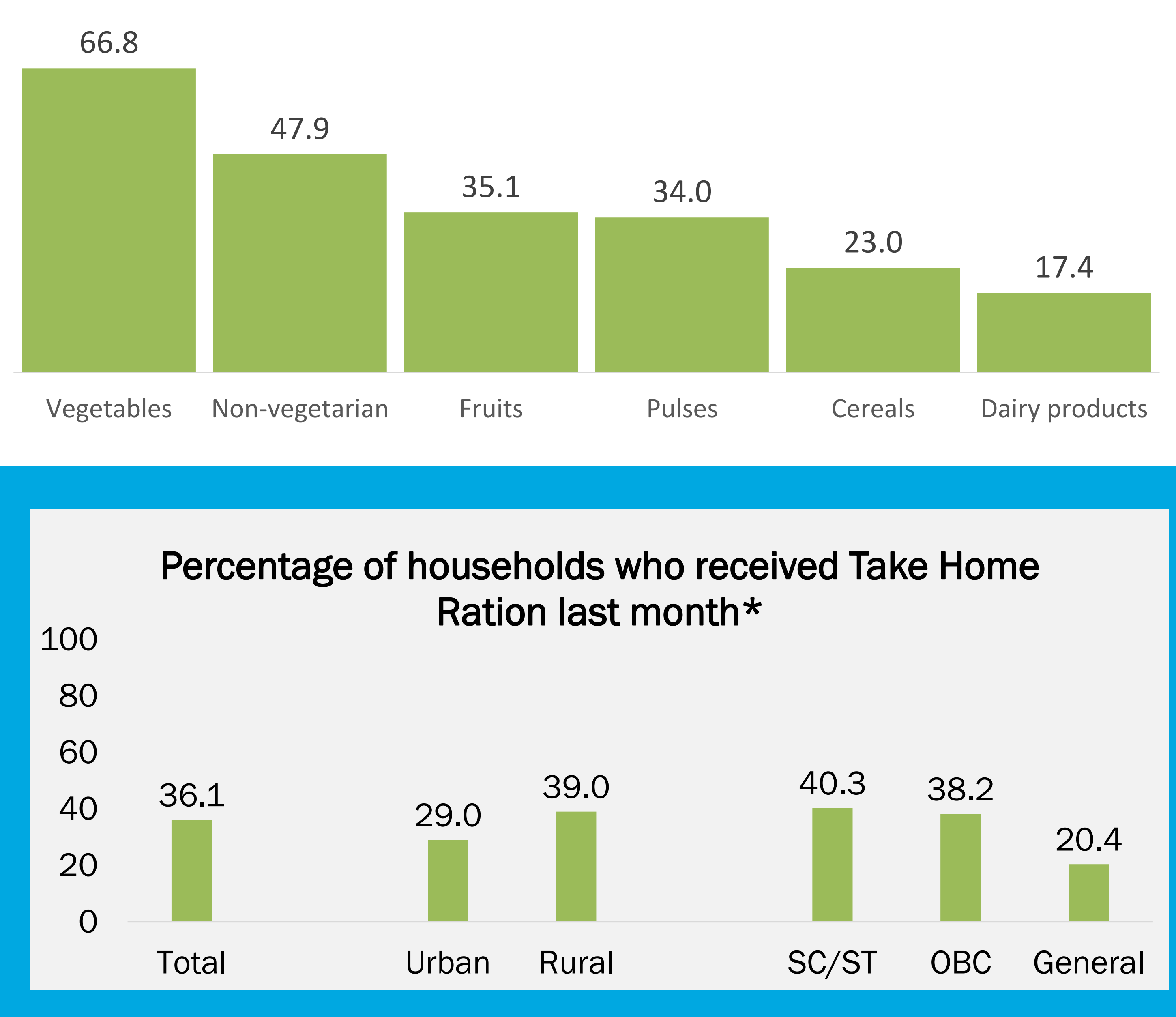

Among households with a pregnant or lactating woman, or a child aged 6-72 months ( $N=391$ );

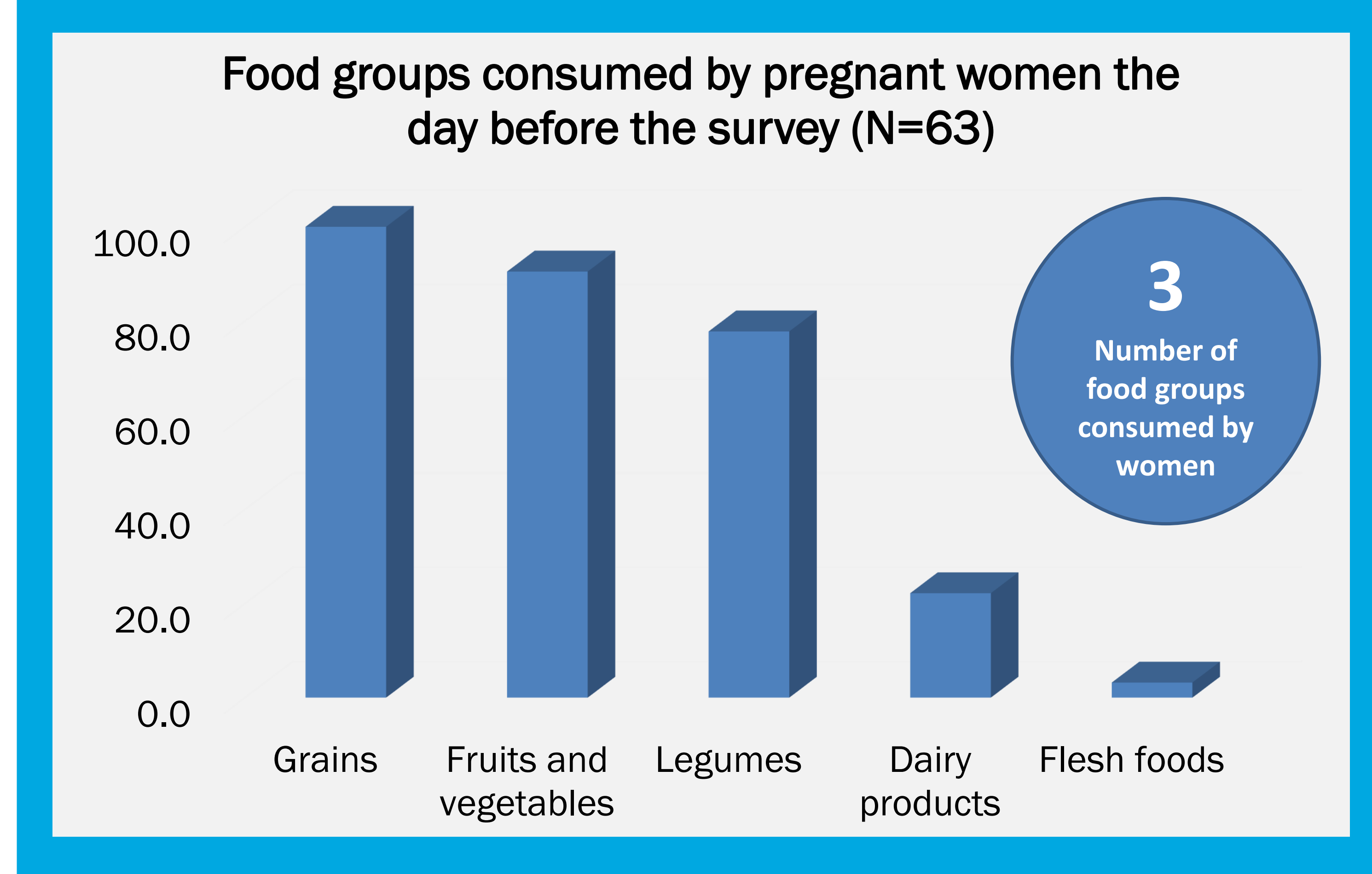

$29 \%$ households with a child aged $6-14$ reported receiving cash in lieu of mid-day meal due to school-going children $(N=176)$ lockdown; higher among rural, marginalised, x A

\section{LIMITATIONS}

Although the study sample is a subset of the state-representative UDAYA SDG cohort of adolescents, the representative nature of the selection could not be retained because of differential phone ownership by adolescents from higher and lower economic strata, mobile number retention/portability, etc. As mentioned in the Method section, the sample is biased towards households with a higher standard of living. The results may thus be interpreted with caution.

\section{CONTACT INFORMATION}

This work was jointly undertaken by Population Council Institute and UNICEF/Bihar.

For more information, contact racharya@popcouncil.org; pash@unicef.org 